\title{
Routine SARS-CoV-2 RT-PCR testing before digestive endoscopy during the peak of the pandemic - a single tertiary center experience
}

\author{
Karolina Novakova ${ }^{a}$, Premysl Falta, Vit Navratil ${ }^{\mathrm{a}}$, Matej Haleka, Marek Vetesnik ${ }^{\mathrm{a}}$, Peter Slodickaa ${ }^{\mathrm{a}}$, Pavel Sauer ${ }^{\mathrm{b}}$, Milan Kolar ${ }^{\mathrm{b}}$, \\ Roman Havlikc, Jana Zapletalovad, Ondrej Urban ${ }^{\mathrm{a}}$
}

Background and Aims. COVID-19 pandemic has impacted on all endoscopy centers in the Czech Republic, that belongs to the most affected countries in the world. The aim of our study was to analyze all procedures following routine RT-PCR testing in our tertiary center during the peak of the pandemic.

Methods. We retrospectively analyzed all procedures performed from October 2020 to January 2021 after a new RT-PCR center had been set up. Main outcomes were type of scheduled procedure, indication, rate of therapeutic interventions and rate of new relevant and malignant findings. Comparison to the same period before the pandemic and SARS-CoV-2 infection in endoscopy staff are also reported.

Results. A total of 1,953 procedures were performed. 624 patients were referred with a negative RT-PCR test and the remaining 1,346 patients were tested in the new center. 1,293 negative tests led to 1,329 procedures. A new relevant finding was reported in 589 (44.3\%), including new malignancy in 56 (4.2\%). 53 patients tested positive (3.9\%). There was a reduction by $9 \%$ in the number of all procedures compared to the same period before the pandemic and an increase in the number of screening colonoscopies and ERCP procedures. In the study period, 9 of 54 staff members contracted SARS-CoV-2 infection.

Conclusions. Routine RT-PCR testing of patients scheduled for elective endoscopy during the peak of COVID-19 pandemic enabled us to essentially maintain our unit productivity, including activities such as screening colonoscopy, endoscopic resection and pancreatobiliary endoscopy.

Key words: digestive endoscopy; coronavirus disease 2019 (COVID-19); severe acute respiratory syndrome coronavirus 2 (SARS-CoV-2); reverse transcription polymerase chain reaction (RT-PCR)

Received: June 21, 2021; Revised: November 1, 2021; Accepted: November 4, 2021; Available online: November 15, 2021 https://doi.org/10.5507/bp.2021.064

(c) 2021 The Authors; https://creativecommons.org/licenses/by/4.0/

${ }^{a}$ Department of Internal Medicine II - Gastroenterology and Hepatology, University Hospital Olomouc, Czech Republic ${ }^{b}$ Department of Microbiology, University Hospital Olomouc, Czech Republic 'Department of Surgery I, University Hospital Olomouc, Czech Republic

${ }^{d}$ Department of Medical Biophysics, Faculty of Medicine and Dentristy, Palacky University Olomouc, Czech Republic Corresponding Author: Ondrej Urban, e-mail: ondrej.urban@fnol.cz

\section{INTRODUCTION}

In December 2019, severe acute respiratory syndrome coronavirus 2 (SARS-CoV-2) leading to the coronavirus disease 2019 (COVID-19) emerged and has since caused one of the worst pandemics in modern history. The Czech Republic belongs to the most affected countries in the world, with persisting high incidence and mortality of COVID-19. With the pandemic impacting on endoscopy units throughout the country during spring and summer 2020 and once again quickly increasing incidence of COVID-19 in September and October 2020, we decided to set up a new RT-PCR center, aiming to keep our endoscopy unit in operation by routine RT-PCR testing before elective endoscopy procedures.

The aim of the study was a retrospective analysis of all endoscopy procedures in our tertiary endoscopy center from October $12^{\text {th }}, 2020$ to January $31^{\text {st }}, 2021$ and a comparison to the same period of the previous two years just before pandemic outbreak.

\section{METHODS}

This was a retrospective analysis of all endoscopy procedures performed in a single tertiary endoscopy unit after routine RT-PCR testing from October $12^{\text {th }}, 2020$ to January $31^{\text {st }}$, 2021. Due to the worsening epidemiological situation, a new RT-PCR center was established in early October 2020 in the building of Department of Internal Medicine II - Gastroenterology and Hepatology, University Hospital Olomouc, dedicated exclusively to test all patients scheduled for endoscopy. The tests were performed by trained nurses from the same department. Concurrently, all cooperating departments and outpatient centers were instructed to test all patients referred to our endoscopy unit by RT-PCR. All tests had to be performed no longer than 48 hours before procedures scheduled for Tuesday through Friday and $72 \mathrm{~h}$ for Monday. Patients with symptoms suggestive of COVID-19 (fever, cough, dyspnea, loss of smell, diarrhea) were referred to a specialized department and not tested at our center. 
Patients with a recent history of RT-PCR positivity of < 90 days were not tested at all. The vaccination program for non-healthcare individuals (elderly $\geq 80$ years) began in February 2021 so no patients had been vaccinated during the analyzed period. Main outcomes of the analysis were demographic characteristics (sex and age), type of scheduled procedure, indication for endoscopy, proportion of therapeutic interventions and new relevant and malignant findings during the endoscopy. The term "relevant finding" includes malignancy, advanced adenoma, ulcer, erosive esophagitis, Barrett's esophagus, celiac disease, signs of portal hypertension, stenosis, complicated diverticular disease, inflammatory bowel disease, ischemic colitis, vascular malformations, biliary or pancreatic stones, biliary stenosis, chronic pancreatitis and pancreatic neoplasia. The term "malignant finding" was defined as histologically confirmed malignancy other than intramucosal colorectal cancer. The number and type of endoscopy procedures in the given period were compared to the same period just before the pandemic outbreak, from October 2019 to January 2020. SARSCoV-2 infection in endoscopy staff members during the analyzed period is also reported. Vaccination for medical professionals did not start until the beginning of January 2021. The study was approved by the Ethics Committee of the University Hospital Olomouc and Faculty of Medicine and Dentistry, Palacky University in Olomouc (reference number 68/21).

Personal protective equipment used during the procedures was stratified according to the European Society of Gastrointestinal Endoscopy (ESGE) position statement ${ }^{1}$. In negatively tested patients, endoscopy staff used a FFP2 mask, gloves, a hairnet, goggles, and a water-proof gown. In positively tested and not postponable cases, a FFP3 mask, two pairs of gloves, a hairnet, a face shield, shoe covers, and a double water-proof gown were employed. In both situations, protective measures were the same regardless of the endoscopy type, except for surgical or FFP2 masks worn by patients during lower endoscopy.
RT-PCR was performed on nasopharyngeal swabs collected in $2 \mathrm{~mL}$ of universal transport media (UTM, COPAN Diagnostics Inc.). Viral RNA isolation was performed on $200 \mathrm{~mL}$ of the swab in UTM using automatic nucleic acid magnetic beads extraction platform Zybio EXM 3000 and Nucleic acid extraction kit (Zybio, Shenzen, China). The final elution volume was $50 \mathrm{~mL}$. RT-PCR was performed using two detection kits: Novel Coronavirus (2019-nCoV) Real-Time Multiplex RT-PCR Kit (LifeRiver, Shanghai, China) and Allplex SARS-CoV-2 Assay (Seegene, South Korea), according to the manufacturer's recommendation. Liferiver kit targets ORFIab, E and $N$ genes and the procedure was as follows: $20 \mathrm{~mL}$ Master Mix, $5 \mathrm{ml}$ isolated RNA, 40 cycles. The detection limit was five copies per reaction. Seegene kit detects RdRP, $\mathrm{S}$ and $\mathrm{N}$ genes in $15 \mathrm{~mL}$ of Master Mix with $5 \mathrm{~mL}$ of isolated RNA during 40 cycles. The detection limit was 10 viral genome equivalents per reaction.

\section{RESULTS}

From October 2020 to January 2021, a total of 1,953 endoscopy procedures were performed. 624 patients were either referred from other centers with a negative RT-PCR test or not tested due to history of recent RT-PCR positivity ( $<90$ days). The remaining 1,346 patients were tested in our new RT-PCR sampling center (male $53.9 \%$, mean age $57.3 \pm 16,0$ years). 1,293 tested negative, leading to 1,329 procedures. 53 patients tested positive (3.9\%). (Fig. 1).

Procedures performed after a negative RT-PCR in our sampling center are shown in Table 1. There were 499 (37.5\%) upper endoscopy, 617 (46.4\%) colonoscopy, 64 (4.8\%) endosonography and 74 (5.6\%) ERCP procedures. The indication for colonoscopy was screening in 78 patients (57 of them for FOBT positivity). In 22 patients $(1.7 \%)$, other procedures (esophageal impedance and manometry, motorized spiral enteroscopy) were performed. 53 patients with a negative test did not present for the

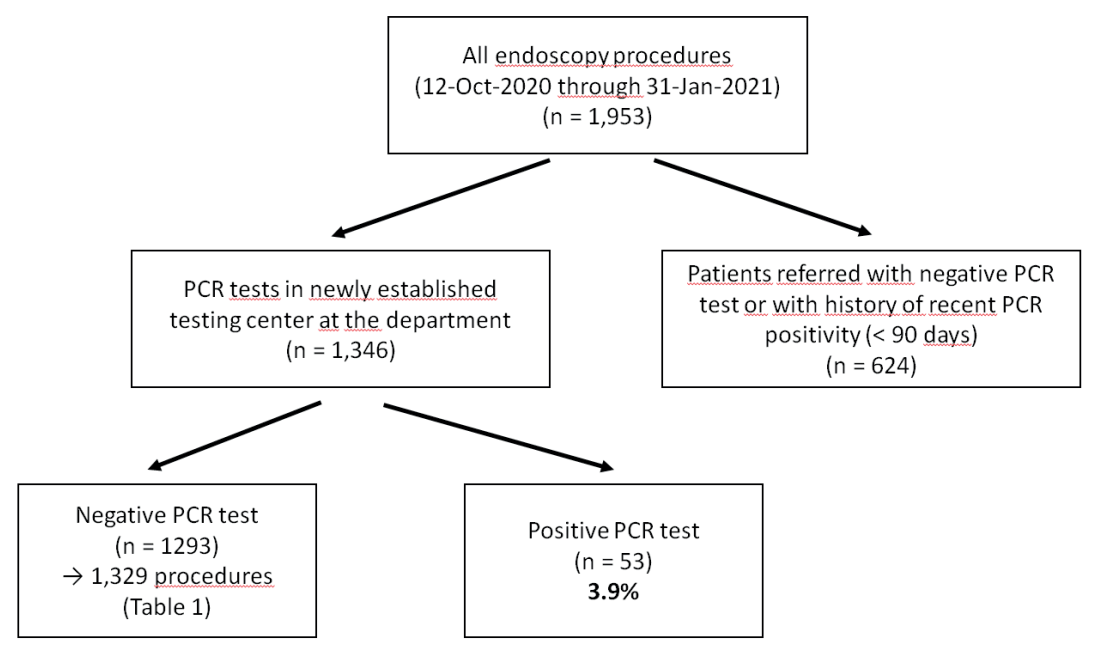

Fig. 1. Flow chart of all endoscopic procedures performed in the study period. 
Table 1. Procedures after negative RT-PCR performed in our RT-PCR center $(n=1,329)$.

\begin{tabular}{|c|c|c|c|c|c|c|}
\hline \multirow{2}{*}{$\begin{array}{l}\text { Procedure } \\
\text { Upper endoscopy }\end{array}$} & \multirow{2}{*}{$\begin{array}{l}\text { Number } \\
\mathrm{n}(\%)\end{array}$} & \multicolumn{2}{|l|}{$\begin{array}{l}\text { Indication } \\
\mathrm{n}(\%)\end{array}$} & \multirow{2}{*}{$\begin{array}{l}\text { Therapy } \\
\mathrm{n}(\%) \\
52(10.4)\end{array}$} & \multicolumn{2}{|c|}{$\begin{array}{l}\text { New Findings } \\
\mathrm{n}(\%)\end{array}$} \\
\hline & & \multicolumn{2}{|l|}{$\begin{array}{l}\text { warning signs - } 49(9.8) \\
\text { other signs - } 216(43.3) \\
\text { surveillance - } 211(42.3) \\
\text { planned ER - } 23(4.6)\end{array}$} & & \multicolumn{2}{|c|}{$\begin{array}{l}\text { relevant }^{1}-255(51.1) \\
\text { malignant }^{2}-12(2.4)\end{array}$} \\
\hline Colonoscopy & $617(46.4)$ & \multicolumn{2}{|l|}{$\begin{array}{l}\text { warning signs - } 78(12.6) \\
\text { other signs - } 117(19.0) \\
\text { screening - } 78(12.6) \\
\text { surveillance - } 307(49.8) \\
\text { planned ER - } 37(6.0)\end{array}$} & $201(32.6)$ & \multicolumn{2}{|c|}{$\begin{array}{l}\text { relevant - } 211(34.2) \\
\text { malignant - } 26(4.2)\end{array}$} \\
\hline Endosonography & $64(4.8)$ & \multicolumn{3}{|c|}{$\begin{array}{l}\text { warning signs - } 4(6.3) \\
\text { other signs - } 6(9.4) \\
\text { surveillance - } 29(45.3) \\
\text { management of known malignancy - } 25(39.0)\end{array}$} & \multicolumn{2}{|c|}{$\begin{array}{l}\text { relevant - } 55(85.9) \\
\text { malignant }-12(18.8)\end{array}$} \\
\hline ERCP & $74(5.6)$ & \multicolumn{3}{|c|}{$\begin{array}{l}\text { warning signs - } 11(14.9) \\
\text { management of known malignancy - } 21(28.4) \\
\text { management of known benign lesion - } 42(56.8)\end{array}$} & \multicolumn{2}{|c|}{$\begin{array}{l}\text { relevant - } 68(91.9) \\
\text { malignant }-6(8.1)\end{array}$} \\
\hline Other procedures & $22(1.7)$ & \multicolumn{5}{|l|}{-} \\
\hline No endoscopy followed & $53(4.0)$ & \multicolumn{2}{|l|}{-} & - & \multicolumn{2}{|l|}{ - } \\
\hline \multicolumn{7}{|c|}{$\begin{array}{l}\text { RT-PCR, reverse transcription polymerase chain reaction; ER, endoscopic resection; ERCP, endoscopic retrograde cholangiopancreatography; } \\
\text { 'relevant finding included malignancy, advanced adenoma, ulcer, erosive esophagitis and Barrett's esophagus, celiac disease, signs of portal } \\
\text { hypertension, stenosis, complicated diverticular disease, inflammatory bowel disease, ischemic colitis, vasular malformations, biliary and pan- } \\
\text { creatic stones and focal pancreatobiliary lesions; }{ }^{2} \text { malignant finding was defined as histologically confirmed malignancy apart from intramucosal } \\
\text { colorectal cancer. }\end{array}$} \\
\hline Procedures (n) & & 12 Oct 2020 - 31 Jan 2021 & $12 \mathrm{Oct}$ & $\operatorname{Tan} 2020$ & ifference $(\%)$ & $P$ \\
\hline Upper endoscopy & & $42.0 \%$ & 1062 & $49.4 \%$ & -23 & $<0.0001$ \\
\hline Colonoscopy & & $37.9 \%$ & 920 & $42.8 \%$ & -19 & 0.002 \\
\hline Screening colonoscopy & & $4.0 \%$ & 63 & $2.9 \%$ & 24 & 0.062 \\
\hline EPE & & $12.6 \%$ & 306 & $14.2 \%$ & -20 & 0.124 \\
\hline EMR/ESD & & $4.0 \%$ & 82 & $3.8 \%$ & -4 & 0.706 \\
\hline Endosonography & & $9.0 \%$ & 192 & $8.9 \%$ & -9 & 0.997 \\
\hline FNB/FNA & & $3.5 \%$ & 72 & $3.4 \%$ & -6 & 0.817 \\
\hline $\mathrm{ERCP}$ & & $10.5 \%$ & 179 & $8.3 \%$ & 15 & 0.017 \\
\hline All & & 1953 & 2149 & & -9 & 0.030 \\
\hline
\end{tabular}

EPE, endoscopic polypectomy; EMR, endoscopic mucosal resection; ESD, endoscopic submucosal dissection; FNB, fine-needle biopsy; FNA, fine-needle aspiration; ERCP, endoscopic retrograde cholangiopancreatography.

endoscopy. In 325 (24.5\%) patients, at least one therapeutic procedure was performed. New relevant findings were reported in $589(44.3 \%)$ and new malignancy was found in $56(4.2 \%)$ cases.

In 53 patients (3.9\%) tested at our center, the RT-PCR test was positive. 28 patients were indicated for upper endoscopy, 17 for colonoscopy, 4 for endosonography and 4 for ERCP. 2 patients underwent endoscopy despite RTPCR positivity (1 ERCP for acute cholangitis, 1 endo- sonography for potentially operable pancreatic cancer). So far (March 31 $\left.{ }^{\text {st }}, 2021\right), 36$ procedures were postponed by 6 weeks on average (range 1-15 weeks) and 15 procedures have not been performed yet.

In the same period, a total of 24 urgent procedures in patients with known COVID-19 were carried out using recommended protective equipment. 10 upper endoscopy and 2 colonoscopy procedures were indicated for acute gastrointestinal bleeding, 9 ERCP procedures for acute 
cholangitis and/or acute biliary pancreatitis and 3 endosonography procedures for potentially operable pancreatic cancer.

Comparison of endoscopic procedures performed in the given period to the same period just before the pandemic outbreak (from October 2019 to January 2020) is shown in Table 2. Both periods included 75 workdays. A reduction in the number of all endoscopic procedures by $9 \%$ was observed. The number of all colonoscopy procedures was reduced by $19 \%$ (741/920), while the number of screening colonoscopies increased by $24 \%$ (78/63) and the number of endoscopic resection procedures decreased by $4 \%$ only. The number of ERCP procedures increased by $15 \%(205 / 179)$.

Our endoscopy staff includes 39 endoscopy nurses and assistants. During the study period, 7 (18\%) of them contracted SARS-CoV-2 virus. In 2 cases, the infection was acquired at home, and in the remaining 5 cases from an unknown source. From a total of 15 active endoscopists, 2 tested positive. It is very likely that both of them acquired the infection from family members infected earlier.

\section{DISCUSSION}

In December 2019, COVID-19 caused by SARSCoV-2 emerged in China. In March 2020, the disease was declared a global pandemic by the World Health Organization $^{2-4}$. The impact of COVID-19 on both the world population health and economy is devastating. According to data published by the Johns Hopkins Coronavirus Resource Center, a total of 123 million cases and more than 2.72 million deaths have been reported worldwide by March 2021. At the same time, the Czech Republic was the second most affected country in the world with a mortality of 227 per 100,000 people $^{5}$.

Following repeated lockdowns and a redirection of healthcare resources towards management of the pandemic, routine healthcare performance has been dramatically altered. Among others, many digestive endoscopy procedures had to be cancelled or postponed. For instance, Patel et al. demonstrated a colonoscopy volume decline in the San Francisco region by 90\% (ref. ${ }^{6}$ ). Repici et al. reported reduced normal endoscopy activities in all but 1 of 42 endoscopy centers in Northern Italy ${ }^{7}$. In their multinational cross-sectional survey of 11 centers from four continents, Rodríguez-Carrasco et al. showed a 55\% reduction of endoscopic resections for neoplastic lesions during lockdown, which was as high as $76 \%$ in severally affected countries ${ }^{8}$. In the Czech Republic, Tacheci et al. showed significant reduction of endoscopy procedures at $86 \%$ of units 9 .

Postponing of endoscopy procedures may result in unwanted consequences. Among them, possible long-term increase of the gastrointestinal cancer is of special concern. As shown by Lee et al., there is an increased risk for any colorectal cancer or advanced stage disease when colonoscopy is delayed by more than 6 months after a positive fecal occult bleeding test ${ }^{10}$. In the United States, a hypothetical suspension of elective colonoscopy for 6 months is predicted to result in delayed diagnosis of 2,800 colorectal cancer cases and 22,000 high-grade dysplasia lesions ${ }^{11}$. A $35 \%$ reduction of newly diagnosed gastrointestinal cancer cases during lockdown in the Netherlands was reported by Lantinga et al. while Manes et a. found a $44 \%$ decline in absolute number of new cancer diagnoses in Northern Italy ${ }^{12,13}$.

Upper endoscopy is considered to be an "aerosol generating procedure" that may lead to increased risk of health care personnel exposure to respiratory pathogens such as SARS-CoV-2 (ref. $\left.{ }^{14}\right)$. Potential inhalation of airborne droplets, conjunctival inoculation or fecal-oral route of transmission lead to increased risk of infection. Infected staff may spread the virus to other colleagues, patients and family members ${ }^{1,15}$. Depending on population viral load, a significant number of patients undergoing endoscopy fall in the category of asymptomatic carriers of SARS-CoV-2. Preventive measures are therefore necessary to avoid spread of infection. Repici et al. first published principles of patient individual risk stratification ${ }^{16}$. Moreover, different professional societies provided guidance to help assure the highest level of endoscopy care and protection against COVID-19 (ref. ${ }^{1,17,18}$ ). Among them, the Czech Society of Gastroenterology (CSG) launched a position statement on March $16^{\text {th }}, 2020$ and an update thereof on December $12^{\text {th }}, 2020$. During the study period, ongoing community transmission of COVID-19 was reported by national authorities all over the Czech Republic. On the national level, positive rate of SARSCoV-2 tests was as high as $41 \%$ while $\mathrm{R}$ number peaked at value 1.3. All patients scheduled for elective endoscopy were therefore considered as high-risk according to the CSG statement and their procedures were to be postponed. Alternatively, patients with negative RT-PCR testing could classify as low-risk and be treated using standard precautions ${ }^{19}$.

In an effort to keep our endoscopy center in operation, we introduced routine pre-endoscopy RT-PCR testing as an adjunct to routine risk stratification based on clinical and epidemiologic factors. The rate of positive results $(3.94 \%)$ was higher than published data from the Stanford University Medical Center $(0.14 \%)$ or Mount Sinai Hospital in New York $(0.97 \%)$ but comparable to reports from Santa Clara County (4.34\%) (ref. ${ }^{20,21}$ ). Surprisingly, it was more than ten times lower than the RT-PCR positivity rate of $41 \%$ in the Czech general population during the study period ${ }^{22}$. This could be explained by testing a specific group of patients indicated for endoscopy and without any symptoms suggestive of COVID-19 selected by pre-test screening. We can also speculate on specific and cautious behavior of these patients before scheduled endoscopy that was often already postponed.

The influence of testing on management of the patients was fundamental. Without routine testing, most of the elective procedures would have been cancelled or postponed. In the study period, we maintained endoscopic care with an only $9 \%$ reduction of the total number of procedures compared to the same period before the pandemic outbreak. The number of colorectal cancer screen- 
ing colonoscopies was even higher by $24 \%$, most likely due to the temporary suspension of the screening program in spring and summer 2020. The number of ERCP procedures also increased by $15 \%$. This may be explained by more frequent referrals from cooperating centers with restricted activity. A steady number of ERCP procedures during lockdown was reported also in the study from the Netherlands. Nevertheless, there was a decreased gastroscopy and colonoscopy volume by $57 \%$ and $45 \%$, respectively ${ }^{12}$. In 36 out of 53 positively tested patients, endoscopy was delayed by 6 weeks on average (range 1-15 weeks) and there were relevant findings in 14 patients including 2 newly detected malignancies (both pancreatic cancer). Interestingly, both patients underwent endoscopy procedure (ERCP and endosonography) despite RT-PCR positivity. In 15 positively tested patients, endoscopy has not yet been performed for different reasons.

In the literature, incorporation of RT-PCR testing as part of risk stratification before elective endoscopy is discussed and supported by some authors ${ }^{23}$. We realize that routine RT-PCR testing may face organizational and economic challenges. In their Czech multicenter survey, Tacheci et al. showed that RT-PCR testing could not be offered to all patients in $86 \%$ units and $44 \%$ had no access to RT-PCR testing at all ${ }^{9}$. As far as costs are concerned, Ebigbo et al. calculated that the incremental cost-effectiveness ratio for prevalence rate $\geq 1 \%$ was the lowest for the strategy of routing testing coupled with use of high-risk protective equipment ${ }^{24}$. We are also aware that the strategy of routine testing is now being affected by ongoing vaccination and emerging herd immunity.

\section{CONCLUSION}

In conclusion, our study demonstrates that with RTPCR testing of patients scheduled for elective endoscopy during ongoing community transmission of SARS-CoV-2 infection, maintaining the productivity of an endoscopy center on the pre-pandemic level is possible, including activities such as colorectal cancer screening programs, endoscopic resections and pancreatobiliary procedures. Introduction of routine RT-PCR testing would depend strongly on local conditions and it is certainly not feasible in all endoscopy centers.

\section{ABBREVIATIONS}

RT-PCR, Reverse transcription polymerase chain reaction; COVID-19, Coronavirus disease of 2019; ER, Endoscopic resection; ERCP, Endoscopic retrograde cholangiopancreatography; EPE, Endoscopic polypectomy; EMR, Endoscopic mucosal resection; ESD, Endoscopic submucosal dissection; FNB, Fine-needle biopsy; FNA, Fine-needle aspiration.

Acknowledgement: The work was supported by the Czech Ministry of Health (DRO FNOL 00098892).
Author contributions: KN: analysis and interpretation of the data, drafting of the article; PF: conception and design, analysis and interpretation of the data, drafting of the article; VN: analysis and interpretation of the data; MH: analysis and interpretation of the data; MV: analysis and interpretation of the data; PSI: analysis and interpretation of the data; PSa: analysis and interpretation of the data, drafting of the article; MK: critical revision of the article for important intellectual content, final approval of the article; RH: critical revision of the article for important intellectual content, final approval of the article; JZ: OU: conception and design, analysis and interpretation of the data, critical revision of the article for important intellectual content, final approval of the article.

Conflict of interest statement: The authors state that there are no conflicts of interest regarding the publication of this article.

\section{REFERENCES}

1. Gralnek IM, Hassan C, Beilenhoff U, Antonelli G, Ebigbo A, Pellise M, Arvanitakis M, Bhandari P, Bisschops R, Van Hooft JE. ESGE and ESGENA Position Statement on gastrointestinal endoscopy and COVID-19: An update on guidance during the post-lockdown phase and selected results from a membership survey. Endoscopy 2020;52(10):891-98.

2. Guan WJ, Ni ZY, Hu Y, Liang WH, Ou CQ, He JX, Liu L, Shan H, Lei CL, Hui DSC, Du B, Li LJ, Zeng G, Yuen KY, Chen RC, Tang CL, Wang T, Chen PY, Xiang J, Li SY, Wang JL, Liang ZJ, Peng YX, Wei L, Liu Y, Hu YH, Peng P, Wang JM, Liu JY, Chen Z, Li G, Zheng ZJ, Qiu SQ, Luo J, Ye CJ, Zhu SY, Zhong NS. China Medical Treatment Expert Group for Covid-19: Clinical Characteristics of Coronavirus Disease 2019 in China. N Engl J Med 2020;382(18):1708-20.

3. Huang C, Wang Y, Li X, Ren L, Zhao J, Hu Y, Zhang L, Fan G, Xu J, Gu X, Cheng Z, Yu T, Xia J, Wei Y, Wu W, Xie X, Yin W, Li H, Liu M, Xiao Y, Gao H, Guo L, Xie J, Wang G, Jiang R, Gao Z, Jin Q, Wang J, Cao B. Clinical features of patients infected with 2019 novel coronavirus in Wuhan, China. Lancet 2020;395(10223):497-506.

4. WHO Director-General's opening remarks at the media briefing on COVID-19 - 11 March 2020. [cited 2021 Mar 14] Available from: https://www.who.int/director-general/speeches/detail/who-director-general-s-opening-remarks-at-the-media-briefing-on-covid19---11-march-2020

5. Johns Hopkins Coronavirus Resource Center. [cited 2021 Mar 14] Available from: https://coronavirus.jhu.edu

6. Patel S, Issaka RB, Chen E, Somsouk M. Colorectal Cancer Screening and COVID-19. Am J Gastroenterol 2021;116(2):433-34.

7. Repici A, Pace F, Gabbiadini R, Colombo M, Hassan C, Dinelli M, Group IG-CW. Endoscopy Units and the Coronavirus Disease 2019 Outbreak: A Multicenter Experience From Italy. Gastroenterology 2020;159(1):363-366.e363.

8. Marta Rodríguez-Carrasco, Eduardo Albéniz, Pradeep Bhandari, Torsten Beyna, Michael J. Bourke, Ahyeon Min, Philip W.Y. Chiu, Simon Chu, Hon Chi Yip, Pierre H. Deprez, Fabian Emura, Alessandro Repici, Noriko Suzuki, Naohisa Yahagi, Yoko Kubosawa, Cesare Hassan, Mário Dinis-Ribeiro: COVID-19 and endoscopic management of superficial gastrointestinal neoplastic lesions: a multinational cross-sectional survey. Endoscopy 2021;53(2):173-77.

9. Tacheci I, Urban O, Lukas M, Rejchrt S, Bureš J, Falt P, Vítek P, Hrdlicka L, Douda T. Impact of the COVID-19 pandemic on endoscopy practice in the Czech Republic - Survey research. Gastroenterologie a Hepatologie 2020;74(3):195-203.

10. Lee YC, Fann JC, Chiang TH, Chuang SL, Chen SL, Chiu HM, Yen AM, Chiu SY, Hsu CY, Hsu WF, Wu MS, Chen HH. Time to Colonoscopy and Risk of Colorectal Cancer in Patients With Positive Results From Fecal Immunochemical Tests. Clin Gastroenterol Hepatol 2019; 17(7):13321340.e1333. 
11. Peery AF, Crockett SD, Murphy CC, Lund JL, Dellon ES, Williams JL, Jensen ET, Shaheen NJ, Barritt AS, Lieber SR, Kochar B, Barnes EL, Fan YC, Pate V, Galanko J, Baron TH, Sandler RS. Burden and Cost of Gastrointestinal, Liver, and Pancreatic Diseases in the United States: Update 2018. Gastroenterology 2019;156(1):254-272.e211.

12. Lantinga MA, Theunissen F, Ter Borg PCJ, Bruno MJ, Ouwendijk RJT, Siersema PD, Trans ITfsg. Impact of the COVID-19 pandemic on gastrointestinal endoscopy in the Netherlands: analysis of a prospective endoscopy database. Endoscopy 2021;53(2):166-70.

13. Manes G, Saibeni S, Pellegrini L, Picascia D, Pace F, Schettino M, Bezzio C, de Nucci G, Hassan C, Repici A and The Fast-Track Endoscopy Study Group (2021). Improvement in appropriateness and diagnostic yield of fast-track endoscopy during the COVID-19 pandemic in Northern Italy. Endoscopy 2021;53(2):162-65.

14. Tran K, Cimon K, Severn M, Pessoa-Silva CL, Conly J. Aerosol generating procedures and risk of transmission of acute respiratory infections to healthcare workers: a systematic review. PLoS One 2012;7(4):e35797.

15. Xiao F, Tang $M$, Zheng $X$, Liu Y, Li X, Shan H. Evidence for Gastrointestinal Infection of SARS-CoV-2. Gastroenterology 2020;158(6):1831-1833.e3.

16. Repici A, Maselli R, Colombo M, Gabbiadini R, Spadaccini M, Anderloni A, Carrara S, Fugazza A, Di Leo M, Galtieri PA, Pellegatta G, Ferrara EC, Azzolini E, Lagioia M. Coronavirus (COVID-19) outbreak: what the department of endoscopy should know. Gastrointest Endosc 2020;92(1):192-97.

17. Gralnek IM, Hassan C, Beilenhoff U, Antonelli G, Ebigbo A, Pellisè M, Arvanitakis M, Bhandari P, Bisschops R, Van Hooft JE, Kaminski
MF, Triantafyllou K, Webster G, Pohl H, Dunkley I, Fehrke B, Gazic M, Gjergek T, Maasen S, Waagenes W, de Pater M, Ponchon T, Siersema PD, Messmann H, Dinis-Ribeiro M. ESGE and ESGENA Position Statement on gastrointestinal endoscopy and the COVID-19 pandemic. Endoscopy 2020;52(6):483-90.

18. COVID-19:ASGE updates for members. In. [cited 2021 Mar 14]

19. Czech Society of Gastroenterology (CSG) Position Statement on Digestive Endoscopy during the COVID-19 Pandemic (1.12.2020). [cited 2021 Feb 21] Available from: https://www.cgs-cls.cz/wpcontent/uploads/2020/12/covid19_ver_8def-1.pdf (In Czech)

20. Dolinger MT, Kumta NA, Greenwald DA, Dubinsky MC. Outcomes of Universal Preprocedure Coronavirus Disease 2019 Testing Before Endoscopy in a Tertiary Care Center in New York City. Gastroenterology 2020;159(5):1962-64.

21. Podboy A, Cholankeril G, Cianfichi L, Guzman E, Jr., Ahmed A, Banerjee S. Implementation and Impact of Universal Preprocedure Testing of Patients for COVID-19 Before Endoscopy. Gastroenterology 2020;159(4):1586-1588.e4.

22. COVID-19: Přehled aktuální situace v ČR. Available from: https:// onemocneni-aktualne.mzcr.cz/covid-19 (in Czech)

23. Gupta S, Shahidi N, Gilroy N, Rex DK, Burgess NG, Bourke MJ. Proposal for the return to routine endoscopy during the COVID-19 pandemic. Gastrointest Endosc 2020;92(3):735-42.

24. Ebigbo A, Rommele C, Bartenschlager C, Temizel S, Kling E, Brunner J, Messmann H. Cost-effectiveness analysis of SARS-CoV-2 infection prevention strategies including pre-endoscopic virus testing and use of high risk personal protective equipment. Endoscopy 2021;53(2):156-61. 